\title{
Management and Organization Review Special Issue 'Celebrating and Advancing the Scholarship of Kwok Leung (1958-2015)'
}

\author{
Call for Papers \\ Guest Editors: \\ Michael Morris, ${ }^{1}$ Zhen Xiong (George) Chen, ${ }^{2}$ \\ Lorna Doucet, ${ }^{3}$ and Yaping Gong ${ }^{4}$ \\ ${ }^{1}$ Columbia University, ${ }^{2}$ Australian National University, ${ }^{3}$ Fudan University, and \\ ${ }^{4}$ Hong Kong University of Science and Technology
}

Submission deadline: May 15, 2016

This is a wide ranging call for papers addressing and extending Professor Kwok Leung's scholarship in cross-cultural research, psychology, and management (see below).

Questions about the special issue may be directed to any of the guest editors. Papers for the special issue should be submitted electronically through MOR's ScholarOne Manuscripts site at http://mc.manuscriptcentral.com/mor and identified as submission to the 'Scholarship of Kwok Leung' special issue. All submissions should follow the 'MOR Author Guidelines', available online at http://journals.cambridge.org/images/fileUpload/documents/MOR_ifc.pdf

The Special Issue will be published on the second anniversary of Professor Leung's passing (MOR 13.3).

\section{Kwok Leung Scholarship Legacy}

Kwok Leung made many significant theoretical and methodological contributions to cross-cultural research in psychology and management (Leung, Bhagat, Buchan, Erez, \& Gibson, 2005; Van de Vijver \& Leung, 1997). He is regarded as a thought leader in many areas of cross-cultural, social, and organizational psychology, including distributive justice (Leung \& Park, 1986), conflict resolution and negotiation (Leung, 1987), harmony maintenance (Leung, Koch, \& Lu, 2002), 
pan-cultural structures of human values and beliefs (Leung \& Bond, 2004), Chinese personality (Cheung, Leung, Fan, Song, Zhang, \& Zhang, 1996), and creativity (Morris \& Leung, 2010).

A central thread in his 30-year career is modeling how culture influences social and organizational behaviors. His earliest empirical contributions tested the model that differences in fairness judgments between individualist and collectivist countries are carried by individual differences in personal values on the dimension of idiocentrism-allocentrism (Leung \& Bond, 1984; Triandis, Leung, Villareal, \& Clack, 1985). Later work found that country differences in conflict resolution decisions were carried more by expectancies than valences (Bond, Leung, \& Schwartz, 1987; Leung, 1987), and by personal perceptions (Morris, Leung, \& Iyengar, 2004), prompting interest in schemas or implicit theories that underlie cultural patterns. To explore how cultural patterns are carried by social assumptions or norms, Kwok pioneered a model of the basic dimensions of social axioms (Leung $\&$ Bond, 2004). His works on fairness judgment and harmony offered exemplary illustrations of how emic and etic research programs inform and stimulate each other (Leung, Brew, Zhang, \& Zhang, 2011; Morris, Leung, Ames, \& Lickel, 1999). A culmination of this sustained inquiry came in a recent conceptual paper (Leung \& Morris, in press) that integrated many of his insights by proposing the conditions, respectively, under which values, schemas, and norms operate: Values play a more important role in accounting for cultural differences in weak situations where fewer constraints are perceived; schemas play a more important role when situational cues increase their accessibility and relevance; and norms play a more important role when social evaluation is salient. This special issue of MOR is dedicated to current research that builds on, elaborates, and extends this stream of work. We welcome manuscripts from a broad range of research areas (e.g., conflict and harmony, negotiation, fairness judgment, leadership, cross-cultural management).

\section{References}

Bond, M. H., Leung, K., \& Schwartz, S. 1992. Explaining choices in procedural and distributive justice across cultures. International Journal of Psychology, 27(2): 21 1-225.

Cheung, F. M., Leung, K., Fan, R. M., Song, W-Z., Zhang, J-X., \& Zhang, J-P. 1996. Development of the Chinese personality assessment inventory. Journal of Cross-Cultural Psychology, 27: 181-199.

Leung, K. 1987. Some determinants of reactions to procedural models for conflict resolution: A cross-national study. Journal of Personality and Social Psychology, 53: 898-908.

Leung, K., \& Bond, M. H. 1984. The impact of cultural collectivism on reward allocation.Journal of Personality and Social Psychology, 47: 793-804.

Leung, K., \& Bond, M. H. 2004. Social axioms: A model for social beliefs in multicultural perspective. San Diego, CA: Elsevier Academic Press.

Leung, K., Brew, F. P., Zhang, Z. X., \& Zhang, Y. 2011. Harmony and conflict: A cross-cultural investigation in China and Australia. Journal of Cross-Cultural Psychology 42(5): 795816.

Leung, K., \& Morris, M. W. In press. Values, schemas, and norms in the culture-behavior nexus: A situated dynamics framework. Journal of International Business Studies, doi: $10.1057 /$ jibs.2014.66 
Leung, K., \& Park, H. J. 1986. Effects of interactional goal on choice of allocation rule: A cross-national study. Organizational Behavior and Human Decision Processes, 37: 111-120.

Leung, K., Bhagat, R. S., Buchan, N. R., Erez, M., \& Gibson, C. B. 2005. Culture and international business: Recent advances and their implications for future research. Journal of International Business Studies, 36: 357-378.

Leung, K., Koch, P. T., \& Lu, L. 2002. A dualistic model of harmony and its implications for conflict management in Asia. Asia Pacific Journal of Management, 19: 201-220.

Morris, M. W., \& Leung, K. 2010. Creativity east and west: Perspectives and parallels. Management and Organization Revieze, 6(3): 313-327.

Morris, M. W., Leung, K., Iyengar, S. S. 2004. Person perception in the heat of conflict: Negative trait attributions affect procedural preferences and account for situational and cultural differences. Asian Journal of Social Psychology, 7: 127-147.

Morris, M. W., Leung, K., Ames, D., \& Lickel, B. 1999. Views from inside and outside: Integrating emic and etic insights about culture and justice judgment. Academy of Management Review, 24: 781-796.

Triandis, H. G., Leung, K., Villareal, M. J., \& Clack, F. I. 1985. Allocentric versus idiocentric tendencies: Convergent and discriminant validation. Journal of Research in Personality, 19(4): 395-415.

Van de Vijver, F., \& Leung, K. 1997. Methods and data analysis for cross-cultural research. Thousand Oaks, CA: Sage. 